\title{
Using system archetypes for problem framing and a qualitative analysis: a case study in Iranian water resource management
}

\author{
$\underline{\text { F. Zare }}^{\mathrm{a}}$, A. Bagheri ${ }^{\mathrm{b}}$, S. Elsawah ${ }^{\mathrm{a}, \mathrm{c}}$ \\ ${ }^{a}$ Fenner School of Environment and Society, Australian National University, Canberra, Australia \\ ${ }^{b}$ Department of Water Resources Engineering, Faculty of Agriculture, Tarbiat Modares University, Tehran, \\ Iran \\ ${ }^{c}$ School of Engineering and Information Technology, University of New South Wales, Canberra, Australia \\ Email:fateme.zare@anu.edu.au
}

\begin{abstract}
Sustainable decision making about water resources needs contextual understanding and analysis of water resources systems. A systemic approach provides a holistic understanding of issues and facilitates conceptualizing of the problems. Applying the archetype lenses to look into water resource problems in Gorganroud-Gharesu basin, we found out the overall dynamics of the problem can be explained using some archetypes, mainly: limits to growth, attractiveness principle, fixes that fail and shifting the burden.
\end{abstract}

The Gorganroud-Gharesu Basin is located in Iran in the eastern part of the southern Caspian Sea (Figure 1). The climate is mild and the annual precipitation ranges from 250 to 450 $\mathrm{mm}$, with easterly regions receiving the most rain. The basin area is $13935 \mathrm{Km}^{2}, 60$ percent of it is mountainous and the rest is plains (Samareh Hashemi et al., 2014). The main economic sectors in Gorganroud-Gharesu are agriculture, services and industry.

The Gorganroud-Gharesu Basin has several problems and each of them has different socioeconomic and environmental impacts. The main problem faced by the GorganroudGharesu Basin is the lack of an integrated management in the face of growing demand.

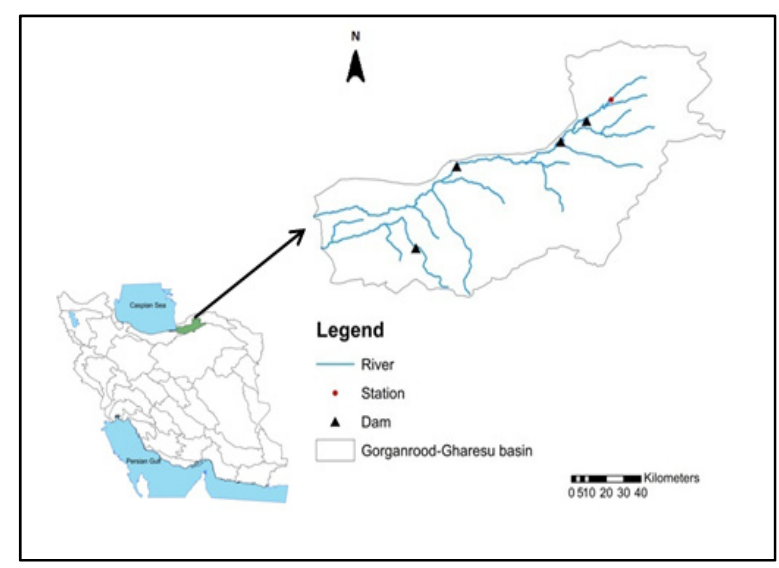

Figure 1. The Gorganroud-Gharesu Basin Water management in the basin is based on short-term responses to the problem without paying attention to the consequences. In other words, despite building four large dams and thousands of wells to meet water demands, the problem comes back more intense each time after a while of meeting previous demand. Also, the number of floods and their damage increased dramatically in the past decades. By investigating the Gorganroud-Gharesu basin's issues and problems, its systemic archetypes were recognized based on facts and data.

The story of archetypes started when the growth of industrial, agriculture and services sectors is threated or limited by not having enough water, this fail has been fixed by making dams and wells and provide more water, unfortunately more supply gives the wrong message to consumers of having sufficient water and lead to encouraging more consumption and problems will continue. The first step to breaking the dynamics of an archetype is to recognize them, their causes and consequences. The system archetypes serve as the means for gaining insights into the underlying system structures from which the archetypal behaviours emerge. This research facilitates conceptualization the model and developing the preliminary dynamic hypothesis for the next step.

Keywords: Limits to growth, attractiveness principle, fixes that fail, shifting the burden, GorganroudGharesu Basin 


\section{INTRODUCTION}

System dynamics (SD) is a thinking model and simulation methodology to help the study of the dynamic behavior of complex systems (Sterman, 2000). SD models are widely used as a tool for examining of the water resource problems which cover the environmental, social and economic systems (Mirchi et al., 2012). Archetypes are one of the tools in system thinking that help to recognize the problems. Archetypes describe dynamic phenomena and "common stories" that occur repeatedly in the diverse sets of behaviour and contexts in the system and as diagnostic tools, they provide insight into the underlying structures from which behaviour over time and discrete events emerge (Braun, 2002). They are powerful tools for identifying problems (Kim, 1992). Archetypes give managers, decision makers and modellers insights into potential future consequences and side effects of policy decisions Archetypes help people see the whole system and recognize the active mechanisms. There are many recognized archetypes. Braun (2002) discussed ten of the most well-known ones which are "Limits to Growth, Shifting the Burden, Eroding Goals, Escalation, Success to the Successful, Tragedy of the Commons, Fixes that Fail, Growth and Underinvestment, Accidental Adversaries and the Attractiveness Principle”.

Mirchi et al. (2012) argue that effective application of a system dynamics model in the study of integrated water resources needs to be preceded by developing a clear picture of the system. This can be achieved through creating a reasonably simplified conceptual model. Identifying archetypes can be valuable in developing broad understandings, and having a broad understanding can contribute to more effectively understanding the root causes of a challenge (Banson et al., 2016). Many studies used system archetypes to make a qualitative analysis of the problem and identify drivers and barriers for sustainable planning in different fields (see Bagheri et al., 2010; Banson et al., 2016; Mirchi et al., 2012; Orefice and Edmilson, 2015). Also, they can be used as a model conceptualization technique.

This paper identifies the archetypes in the case study basin from causal loops of problems and expounds their message regard to water resource management as a step toward the conceptualization phase for model development. So, the preliminary dynamic hypothesis can be developed based on them. Furthermore, we will demonstrate, by using the Gorganroud-Gharesu case study, the value that system archetypes can offer to understand complex water resource management problems.

\section{METHODOLOGY}

In order to develop a SD model, researchers first need to understand the problem structure, or the set of variables and causal links that derive the problem behavior (Sterman, 2000). To achieve a comprehensive view of the Gorganroud-Gharesu Basin we went through the following steps:

1. Field visits

2. Study the trend of related socioeconomic and environmental data during the time

3. Review documents and research reports on environmental, water resource, economic and social aspects of the basin

4. Discussing the first identified problems and their definition with experts

5. Identify the main causal loop diagrams

6. Identify archetypes

In the fourth step, the primary results were discussed with Gorganroud-Gharesu's decision makers and technical experts in different related fields with a verbal and face to face interviews to ensure that we covered the main problems. Then, we have used system dynamics to identify the main problems and probe how they are connected to each other and how to improve policymaking in the basin. We will discuss the results in the following section.

\section{ARCHETYPES AS LENSES}

As mentioned, the overarching problem in the Gorganroud-Gharesu basin is the lack of integrated management in the face of growing demand for water. We identified "Limits to growth, Attractiveness principle, Fixes that fail and Shifting the burden" as useful archetypes for explaining the problems that face the basin. Based on information and data from the basin, we have looked at problems using the archetypes as lenses and discussed them in this section. 


\subsection{Growing water consumption problem (Limits to growth archetype)}

During the last 40 years, the basin has experienced dramatic population growth, as shown in Figure $2^{1}$. Also, Water consumption by different sectors has increased significantly (Figure 3). It is obvious that the system is using the limited water resource for development and growth. The "Limit to growth" archetype usually applies in this situation (Braun, 2002). The Limits to growth archetype states that a reinforcing process of growth will meet a balancing process as the limit of that system is approached (Braun, 2002).

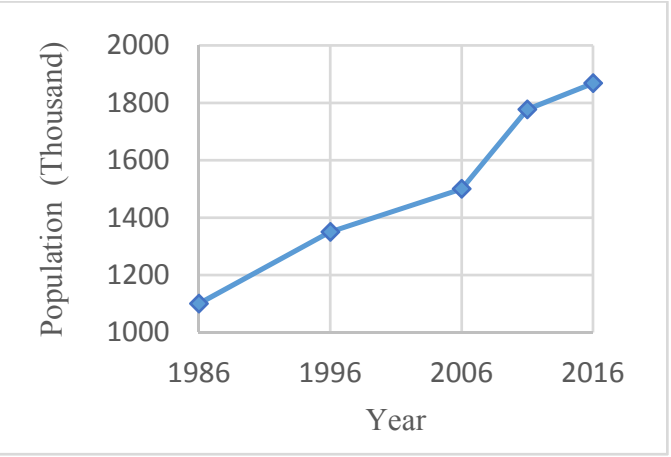

Figure 2. Population growth (Statistical Center of Iran, 2016)

Figure 4 illustrates how increased population causes growth in economic activities (R2.1) and this reinforcing loop causes greater water use - as the water is needed to meet the domestic and economic activities needs (B2.1 and B2.2). Furthermore, water resources are limited and will control the growth of the population and economic activities in the basin (B2.1 and B2.2). Figure 5 is an expansion of Figure 4, showing in more detail the main three economic activities (agriculture, industry and services sector) in the basin and water resources limitation which make a Limit to growth archetype. Water is a vital driver for all of reinforcing loops. Because economic activities are dependent on water use, they will face a limitation

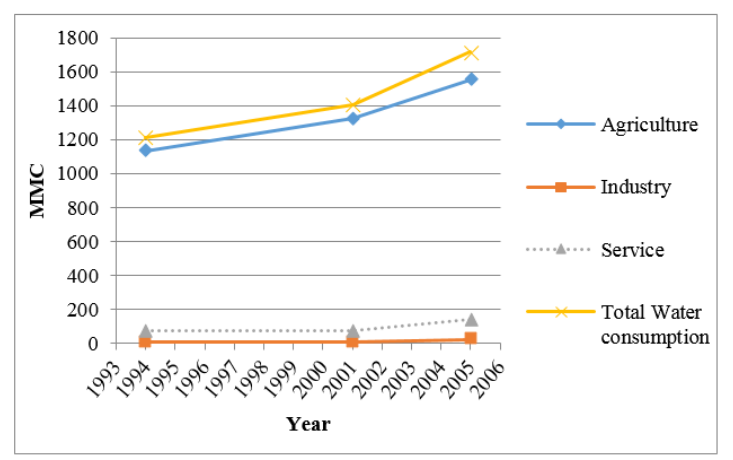

Figure 3. Water consumption of different sectors (Jamab, 2001, 1995; Kankash Omran Company, 2005)

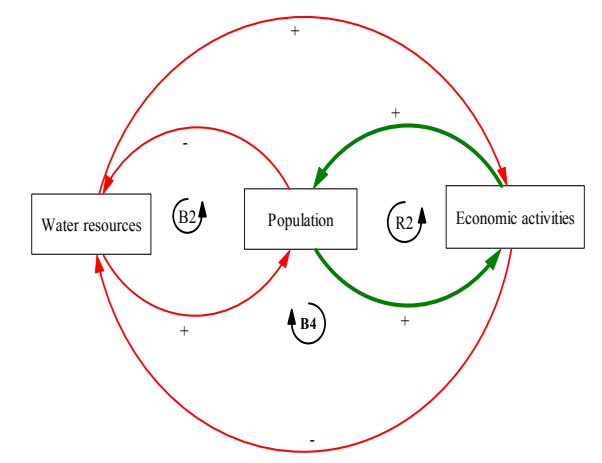

Figure 4. Water resources limit to growth

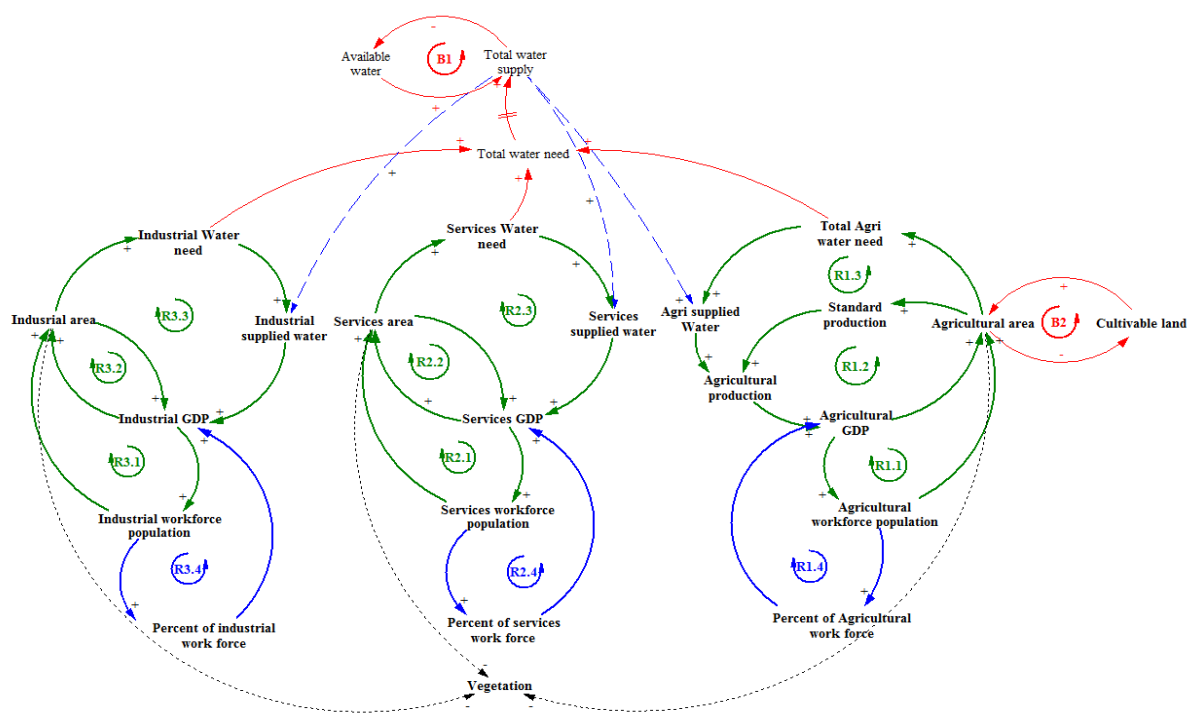

Figure 5. Water resources limit to economic activities growth

1 Figure 2 shows the population growth in Golestan province which covers more than 90 percent of the basin are and represent 
sooner or later (B1). Supplying water for each sector has helped them to increase gross domestic product (GDP) (R1.3, R2.3, and R3.3) and has created more jobs (R1.4, R2.4, and R3.4). In the case of the agriculture sector, the growth faces two limitations: available water (B1) and cultivable lands (B2). By supplying more water with building more dams and wells, the agriculture sector has expanded and increases its GDP, which means there is more money for development and cultivating more area. Changing the land use into the agricultural area has decreased the vegetation area. By developing the agriculture area, water demand has increased (R1.3 and R1.2). Also, development in the sector has provided more jobs (R1.4).

Figure 3 shows the increase of water consumption (which supports the active reinforcing loops (R1.3, R2.3 and R3.3). Expansion of economic activities usually ends up in using more area (for making factories, buildings and etc.). In this regard, Samareh Hashemi et al. (2014) reported that in the basin bare land and forest lands have changed into the agriculture and urban (domestic, services and industry) which supports R3.2, R3.3 and R1.3 loops. The agriculture sector is the largest water consumer in the basin with the increase in water usage about $40 \%$ over eleven years (Figure 3 ). Table 1 shows that in the year 2007, water created less job opportunity and had less water productivity compared to 2001 in all sectors. Generally, water productivity in the services sector is the highest and in the agricultural sector is the lowest one (Table 2). Finally, the water productivity has not increased at the same rate as water consumption which has increased in all sectors. Also, decreasing job opportunity per used water occurred in all sectors that can be a result of using better technology (Table 1).

Table 1. Job opportunity, water productivity and consumption in the Gorganroud-Gharesu basin (Mahab Ghods Co., 2010)

\begin{tabular}{|c|c|c|c|c|}
\hline Sector & Year & $\begin{array}{c}\text { Job opportunity per } \\
\text { used water (Person } \\
\text { per MCM) }\end{array}$ & $\begin{array}{c}\text { Water } \\
\text { Productivity } \\
\text { (Rials per cubic } \\
\text { meters) }\end{array}$ & $\begin{array}{c}\text { Water } \\
\text { consumption } \\
\text { (MCM) }\end{array}$ \\
\hline \multirow{2}{*}{ Agriculture } & 2001 & 124 & 1233 & 1314 \\
\cline { 2 - 6 } & 2007 & 102 & 944 & 1568.22 \\
\hline \multirow{2}{*}{ Industry } & 2001 & 8889 & 55143 & 10.5 \\
\hline \multirow{2}{*}{ Service } & 2007 & 7688 & 45167 & 18 \\
\hline & 2001 & 1495 & 28004 & 100.7 \\
\hline & 2007 & 1368 & 27000 & 138.15 \\
\hline
\end{tabular}

Industry and services sectors have relatively high water productivity, which raises GDP and creates jobs with less water use, and the basin's water productivity increased during 2001-2007, during the time agriculture employment and GDP decreased. Despite these facts, the water allocation policy in the basin prioritizes the agricultural allocation and there are some plans to build more dams (Golestan Regional Water Authority, 2017a) to cover water needs. Considering Figures 2-5, this policy could end up reducing water productivity in agriculture and water shortage in other sectors and slowing down their reinforcement system.

\subsection{Water, land and environment problems (Attractiveness principle archetype)}

Economic development and population growth amplify each other (R2) but this expansion needs natural resources such as land and water which are limited and will eventually constrain the growth (Figure 6). Development in economic activities is influenced indirectly by available water as a limiting condition (B4) and the presence of pollution entered into the environment and land use changes (B1 and B5). All the natural resources in the basin (water resources, water quality limitation on dissolving pollution, limited cultivable land, land use constraints, erosion and sedimentation) will limit the development if decision makers don't pay attention to their capacity. Each of these limitations can cause the system to collapse.

Braun (2002) suggests that the Attractiveness

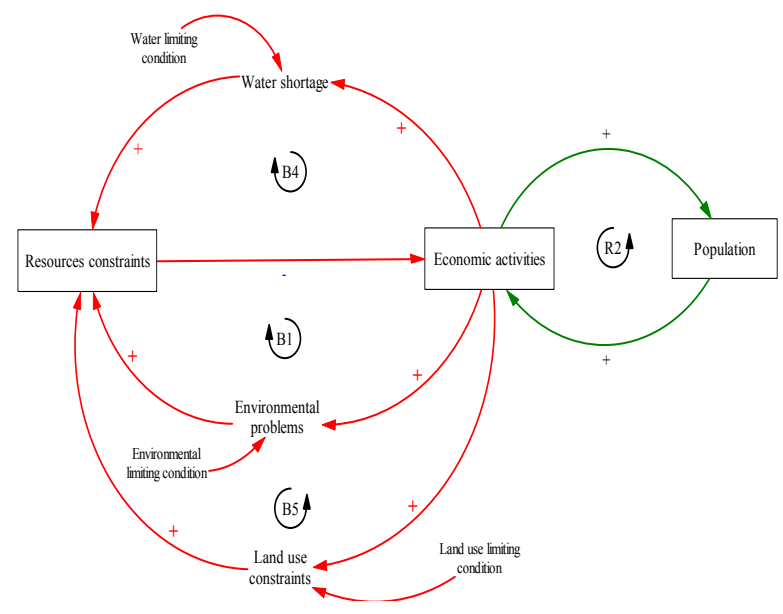

Figure 6. Attractiveness Principle: Population

principle archetype might apply to this situation. This archetype has is similar to the Limits to Growth archetype with the addition of multiple slowing actions. Reaching each of the limitations could be seen as a separate problem but with this archetype lens, it is clear that all of these problems are symptoms of one main problem which is expansionistic thinking in economic activities and population. The symptoms of this archetype in the 
Gorganroud-Gharesu basin is increasing water consumption (Figure 3), land use change and deforestation (Samareh Hashemi et al., 2014) as well as water pollution and environmental degradation (Mahab Ghods Co., 2010). Environmental limits usually cannot be removed and decision makers should manage economic activities development and population growth within those limits, and making compromises among the basin's development goals and resources.

\subsection{Supply-demand continues mismatch problem (Fixes that fail archetype)}

During the past four decades, water supply from surface and groundwater increased dramatically (Figures 810). However unconstrained water supply in the basin led to more water demand. There has been a tripling of surface water supply and a fourfold increase in the number of the wells (Figures 8-10). Also, more than 15000 illegal wells exist in this province (Isna, 2016). It is obvious that during the past 40 years the basin's water shortage problem did not solve by adopting the supply approach and we need to stop this 'Fixes that fail' type of management in the basin.

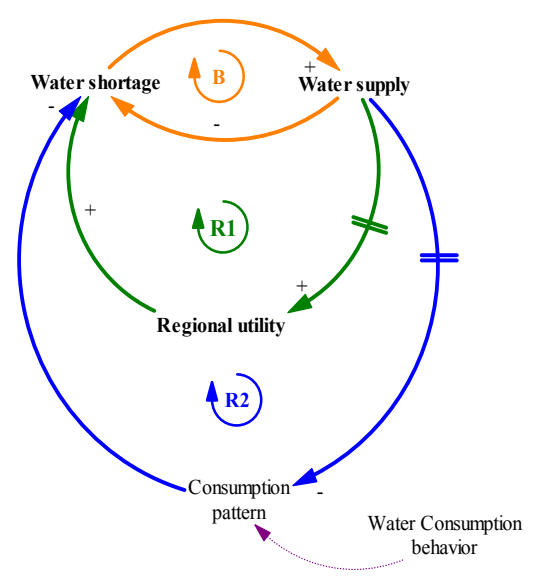

Figure 7. Fixes that fail: water supply

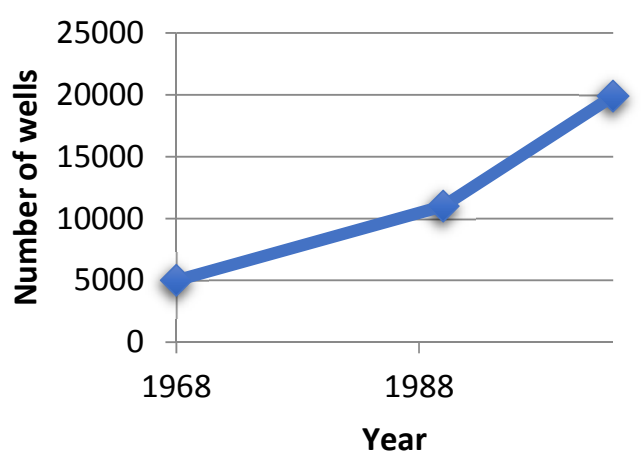

Figure 8. Number of the wells (Mahab Ghods Co., 2010)

Figure 7 shows that any time a shortage of water was fixed by increasing the amount of supply (B), the demand for water subsequently grew (R1). After building many dams and thousands of wells, the problem still exists. By fixing the problem without any supplementary plan, people get the pseudo feeling of having enough water so the consumption pattern will not change (R2). This situation represents the 'Fixes that fail' archetype which happens when a short-term and quick solution is used to relieve a symptom (Kim, 1992; Mirchi et al., 2012). This strategy neglects to pay attention to problem drivers so the problem symptom returns to its previous level or becomes worse (Senge, 1990). These quick fixing solutions are usually useful over the short-term but will strengthen the reinforcing loops in the system and the problem will return bigger and stronger if there were not any supplementary long-term plans.

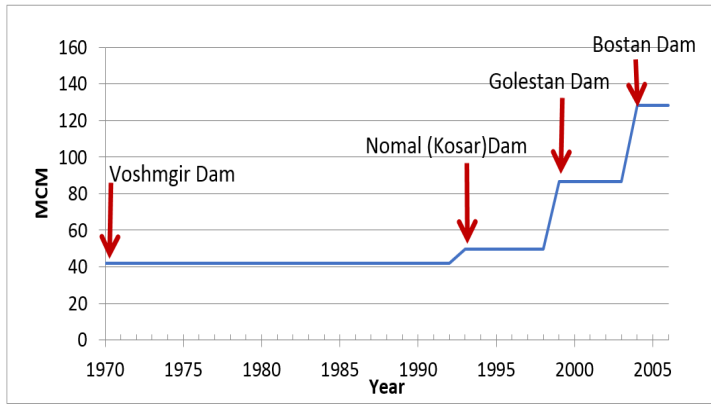

Figure 9. Surface water supply (Golestan Regional Water Authority, 2017)

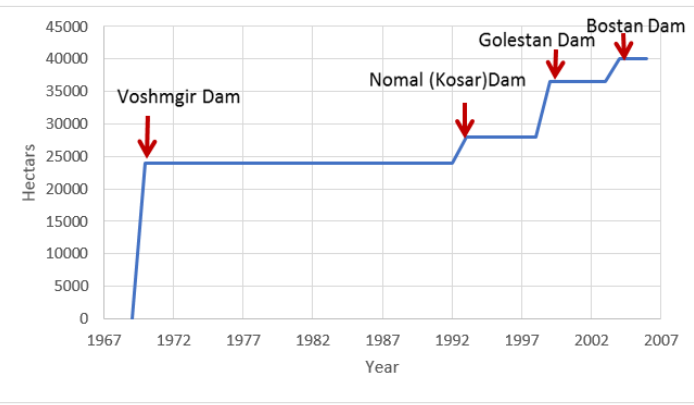

Figure 10. Irrigated farm by supplied water from Dams (Golestan Regional Water Authority, 2017)

\subsection{Flood problem (Shifting the burden and Fixes that fail archetypes)}

There are frequent major floods in the basin which cause a lot of damage. Samareh Hashemi et al. (2014) have found that damage in terms of lost lives and damage to infrastructures has increased in the study area. Dams and reservoirs were built to control floods and reduce the damage (Figure B1). With reducing the impact of the problem, the main reasons for the problem will be forgotten so the development loop will work and more 
land use changes will continue (R2). Then, in time more floods will occur (B2). These three loops (B1, B2 and R2) are an example of the 'Shifting the burden' archetype.

The Shifting the burden archetype usually happens when a symptom of the problem is addressed and drives attention away from fundamental solutions. Figure 11 shows that when a short-term structural solution is used to solve a flood problem and the desirable results obtained in the short-term end, so the long-term and fundamental solution will be considered less. In fact, gaining the short-term results will prevent people from paying attention to managing land use and preventing vegetation changes. Therefore, short-term solutions need to be implemented with the support of long-term ones to ensure that the problem will be solved fundamentally.

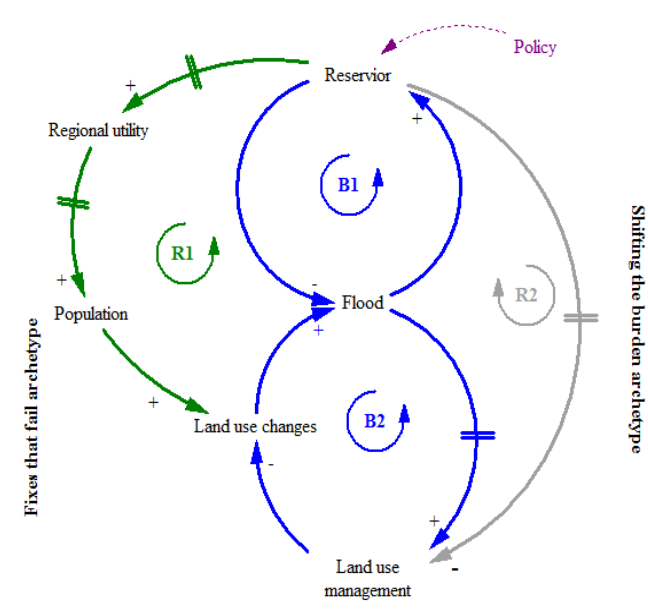

Figure 11. Shifting the burden and fixes that fail: Flood

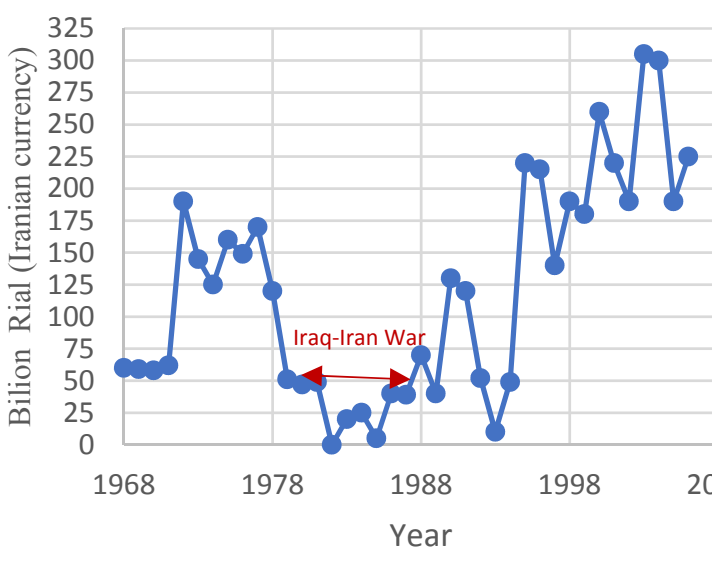

Figure 12. Government investment trend in water resources development projects in the GorganroudGharesu (Mahab Ghods Co., 2010)

Figure 12 shows the amount of Rial (Iranian currency) that the government has invested in water resources development projects in the Gorganroud-Gharesu which generally has increased over time- except during the Iran-Iraq war time 1980-1988. This figure shows tend to the construction solutions in the basin. Simultaneously, there is a 'Fixes that fail' archetype evident in Figure 11, building the reservoirs means more water supply, so the regional utility will increase and it will attract more people through migration, and therefore increases the population. Based on Figures 4 and 5, an increase in population means more economic activity and more land use changes which will cause more floods (Samareh Hashemi et al., 2014).

\section{CONCLUSION}

We have identified and analysed a set of archetypes in the Gorganroud-Gharesu basin (Table 2). Four different types of generic archetypes were used to explain the basin's problems. This paper has suggested that the system archetypes have much more to offer in water management, as they will give decision makers a wider picture of the system which is essential for integrated management. Archetypes can facilitate and accelerate management learning. Also, sometimes stakeholders may find it difficult to describe the variables that influence problem dynamics. Archetypes can be a useful way to step into this discussion. Using system archetypes for interpretation of systems behaviour has its own limitations, such as the risk of force-fitting them onto a problem. By doing this systemic analysis, we gained sufficient information and knowledge about the basin to develop a conceptual model, and then numerical model. Then, looking the problems through the archetypes lenses helped us more easily gain a holistic view of the basin water issues. Table 2 illustrates all existing archetypes in the basin and can be used as a guide to facilitate conceptualization the model and to develop a preliminary dynamic hypothesis for the next step. 
Zare et al., Using system archetypes for problem framing and a qualitative analysis

Table 2. The Gorganroud-Gharesu Basin's archetypes

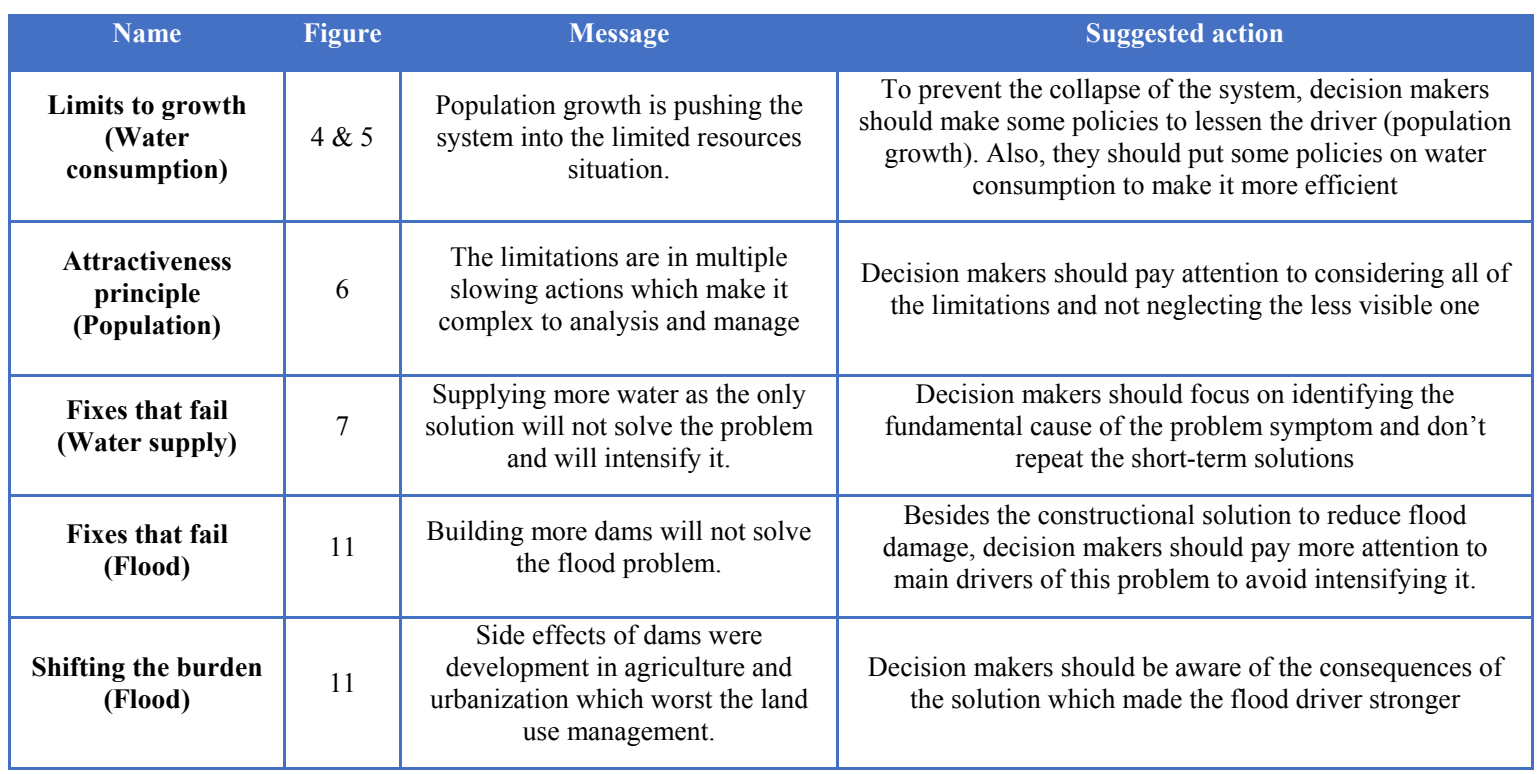

\section{ACKNOWLEDGMENT}

The authors had the opportunity to consult with the Iran Master plan committee members and Mahab-Ghods Company experts who were studying on the basin for years and also some of Gorgan Water Authority members.

\section{REFERENCES}

Bagheri, A., Darijani, M., Asgary, A., Morid, S. (2010). Crisis in Urban Water Systems during the Reconstruction Period: A System Dynamics Analysis of Alternative Policies after the 2003 Earthquake in Bam-Iran. Water Resour. Manag. 24, 2567-2596. doi:10.1007/s11269-009-9568-1

Banson, K.E., Nguyen, N.C., Bosch, O.J.H. (2016). Using System Archetypes to Identify Drivers and Barriers for Sustainable Agriculture in Africa: A Case Study in Ghana. Syst. Res. Behav. Sci. 33, 79-99. doi: $10.1002 /$ sres. 2300

Braun, W. (2002). The system archetypes. System 2002, 27.

Golestan Regional Water Authority (2017). Golestan water company webpage [WWW Document].

Isna, 2016. Golestan Water company CEO interview [WWW Document]. URL http://www.isna.ir/news/95050119758

Jamab (2001). Climate Adaptation Report.

Jamab (1995). Water Master Plan Report.

Kankash Omran Company (2005). Gorganroud Report.

Kim, D.H. (1992). System Archetypes I.

Mahab Ghods Co. (2010). Synthesis report of Gorganroud-Gharesu, Updating National water master plan.

Mirchi, A., Madani, K., Watkins, D., Ahmad, S. (2012). Synthesis of System Dynamics Tools for Holistic Conceptualization of Water Resources Problems. Water Resour. Manag. 26, 2421-2442. doi:10.1007/s11269-012-0024-2

Nabavi, E., Daniell, K.A., Najafi, H. (2017). Boundary matters: the potential of system dynamics to support sustainability? J. Clean. Prod. 140, 312-323. doi:10.1016/j.jclepro.2016.03.032

Orefice, R., Edmilson, M. (2015). System Dynamics - A Bibliometric Analysis of System Dynamics Review, in: 33rd International Conference of the System Dynamics Society. Cambridge, Massachusetts, USA, pp. 2456-2478.

Samareh Hashemi, M., Zare, F., Bagheri, A., Morid, A., Hashemi, M.S., Zare, F., Bagheri, A., Moridi, A. (2014). Flood Assessment in the Context of Sustainable Development using the DPSIR Framework. Int. J. Environ. Prot. Policy 2, 41. doi:10.11648/j.ijepp.20140202.11

Senge, P.M. (1990). The fifth discipline: The art and practice of the learning organization. Doubleday/Currency., New York.

Statistical Center of Iran (2016). Statistical Center of Iran [WWW Document]. URL https://www.amar.org.ir/english (accessed 3.7.17).

Sterman, J.D. (2000). Business Dynamics: Systems Thinking and Modeling for a Complex World, Management. Irwin/McGraw-Hill, Boston. 